\title{
LA FORMACIÓN Y EL DESARROLLO DEL EMPRENDIMIENTO EN EL SECTOR SOLIDARIO
}

\author{
The Formation and the Development of the Entrepreneur \\ in the Solidarity Sector
}

\author{
Lourdes E. Osorio Bayter* \\ Recibido: 29 de febrero de 2008 - Revisado: 17 de abril de 2008 - Aceptado: 23 de mayo de 2008
}

\begin{abstract}
Resumen
El presente artículo es una reflexión fruto del resultado de dos investigaciones previas descriptiva, evaluativa y analítica, que permite acercarnos a una abstracción sobre la importancia del talento humano como factor determinante para el desarrollo regional y la competitividad empresarial, encuadrado en las estructuras de funcionamiento colectivo como sistema social, capaz de difundir y utilizar el conocimiento a manera de eje fundamental en el avance productivo, económico y social.

Por tanto, las instituciones educativas, específicamente las universidades, desempeñan un papel importante en un escenario estratégico, desde la óptica de la disertación, el aprendizaje, los niveles de desarrollo humano, la investigación, la innovación y la inculcación del trabajo en equipo o asociativo, con valores y principios, a fin de estimular el emprendimiento y el desarrollo empresarial, mejorando el desempeño de las capacidades del talento humano para convertirlo en activo y patrimonio trascendental para la organización. Este capital humano, formado y fortalecido, será impulsor para la competitividad regional y nacional, convirtiéndose en un apoyo organizacional con altos niveles de productividad, generador de nuevas oportunidades y desafío institucional en cada uno de los procesos sociales, en busca de alternativas capaces de promover el desarrollo comunitario sostenible.
\end{abstract}

\footnotetext{
PhD(C) en Economía y Administración de la Universidad de Sevilla. Docente de planta y coordinadora del Grupo de Investigación en Ciencias Administrativas de la Universidad Autónoma de Occidente. Correo electrónico: leosorio@uao.edu.co.

Agradecimientos: por su colaboración en el desarrollo del presente documento, a la joven investigadora de la Universidad Autónoma de Occidente Silvia Elena Rodríguez; por su aporte, al doctor Juan C. Montejo Caicedo; y por sus valiosas sugerencias, al PhD. Harold Banguero Lozano.
} 


\title{
Palabras clave
}

Solidaridad, academia, desarrollo empresarial.

\begin{abstract}
This article is the result of two previous investigations of descriptive, evaluative and analytical characteristics, that allow us to identify the importance of the human talent as decisive factor for the regional development and the managerial competitiveness, framed in the structures of collective operation as social system, able to diffuse and to use the knowledge by way of fundamental axis in the productive, economic and social progress.

Therefore, the educational institutions, specifically the universities, inside a strategic scene, play an important role from the lecture perspective, the learning, the levels of human development, the investigation, the innovation and the importance of the work in team or associative, with values and principles, with the purpose of stimulating the entrepreneur and the managerial development, improving the acting of the capacities of the human talent to convert it in active and momentous patrimony for the organization. This human, formed and strengthened capital, it will be impeller for the regional and national competitiveness, transforming into an organizational support with high levels of productivity, source of new opportunities and institutional challenges in each one of the social processes, in search of alternatives able to promote the sustainable communitarian development.
\end{abstract}

\section{Key words}

Solidarity, Academy, Business development.

\section{Introducción}

En la era del conocimiento, de las nuevas tecnologías y del vertiginoso proceso de globalización, el capital intelectual se convierte en factor clave de la empresa. Identificar este conjunto de activos intangibles de una organización puede llegar a generar un valor estratégico de competitividad sostenible, siempre y cuando sea tratado como factor de producción e innovación. Por tanto, analizar cómo la formación y el conocimiento del talento humano se constituyen en ejes trascendentales sostenibles mediante el desarrollo del liderazgo gerencial de las personas que se encuentran al frente de las empresas, sean o no de carácter lucrativo, se hace necesario en esta aceleración de los últimos años, debido a la transformación hacia mercados más abiertos, especialmente para los países de América Latina. Esto obliga a generar nuevas estrategias, aun más para aquellas empresas que tienen el reto de mantener el equilibrio entre la empresa realizable económica y socialmente comprometida. Es así como la adecuada educación y capacitación que reciban los empresarios en formación hoy se verán reflejadas en el futuro mediante el proceso de acumulación de conocimiento.

Desde principios de este siglo ha habido cambios importantes en casi todos los ámbitos y formas de vida, determinados por el constante avance del desarrollo de la ciencia, la tecnología y las telecomunicaciones, que impulsan procesos de globalización económica, laboral y cultural, los cuales plantean nuevos requisitos tanto de formación como de actualización, y nuevos perfiles profesionales que deben tener características de conocimientos, habilidades, actitudes y valores que no siempre se consideran en los procesos formativos de las universidades. Por tanto, la vinculación de las instituciones de educación superior con el sector productivo, y con la misma sociedad es de gran importancia para ambos. 
Mirar hacia una economía alternativa que impulse formas de asociación y que garantice el desarrollo a partir de un modelo de autogestión y de iniciativas productivas, con la participación de agentes locales, ya sea como resultado de una idea o de una investigación conducentes a satisfacer necesidades básicas, muy probablemente disminuirá las intervenciones paternalistas del Estado, al tiempo que impulsa a la comunidad hacía una actitud de progreso colectivo y prosperidad familiar.

En los países de gran desarrollo económico, el tercer sector o sector de la economía solidaria desempeña un rol importante y representa un grupo de entidades que, articuladas en torno a unos objetivos de beneficio social, no sólo en generar empleo, sino también brindar bienestar para la población y su economía, buscan solidariamente reducir los flagelos que se convierten en barreras de desarrollo y crecimiento para un país.

La economía solidaria se ha mostrado eficaz en la generación de calidad del empleo. En los últimos años, por ejemplo, este sector ha conseguido unos índices por encima de la Economía Convencional en España (Cepes, 2007). Además, existe mayor compromiso por el desarrollo local, mayor equidad y cohesión social', lo cual en Europa es una garantía de éxito de la experiencia integracionista.

En Colombia, el sector de la Economía Solidaria contaba con cerca de 9.000 entidades en 2007, entre cooperativas, fondos de empleados y asociaciones mutuales, que contribuían a la redistribución del ingreso y a reducir los niveles de pobreza, consolidándose como una fuente generadora de empleo, convirtiendo la economía social como herramienta para luchar contra la desigualdad social y el subdesarrollo².

1 La Unión Europea es el único ejemplo de integración regional que fomenta la cohesión social; es un proyecto de sociedad. En el ámbito latinoamericano, la desigualdad social y la liberalización económica no ayudan a la cohesión social; por ello, se deben mejorar las políticas sociales y desarrollar el capital humano, educándolo y capacitándolo

2 El Cooperativismo, herramienta social contra el subdesarrollo. EI Tiempo, jueves 17 de mayo de 2007.
Con el sector solidario existen múltiples posibilidades de crear empresas diversas y productivas, que buscan aunar esfuerzos, recursos y aglutinar grupos no atendidos o sencillamente desprotegidos por el Estado y por el sector empresarial privado capitalista, y es allí donde aparecen las oportunidades de asociatividad, el emprendimiento productivo y la innovación en actividades económicas con beneficio común, de cooperación, y no de competencia.

Este espíritu empresarial en un ambiente solidario no sólo combate el desempleo, sino también permite generar clusters que a través de las economías de escala reducen costos de operación y, sobre todo, permiten a sus miembros la oportunidad de aprender y actuar como unidad en propuestas crediticias y, en general, de fomento sectorial.

Por otra parte, el fomento al emprendimiento conlleva el desarrollo de habilidades y capacidades del talento humano, cuyas competencias se habrán de desarrollar para que las organizaciones alcancen un mayor nivel de competitividad. Entonces, es interesante observar cómo en las unidades de negocios solidarias el ser humano y la sociedad en sí son el centro de su existencia y beneficio, en el que prima la persona sobre el capital.

Finalmente, la universidad, por su naturaleza intrínseca, se convierte en un elemento fundamental en el fomento del espíritu empresarial, así como en un eslabón importante del desarrollo de conocimientos, valores y formación del individuo. Este capital humano es la razón de ser esencial del éxito de cualquier organización, permitiéndole autoexigirse, comprometerse y responsabilizarse en la construcción del tejido social. Es necesario recordar que las universidades forman individuos capaces de adaptarse al cambio y la volatilidad de las variables sociales. 


\section{El aprendizaje como eje para la competitividad social: la formación del talento humano para el desarrollo regional y empresarial}

El escenario académico integrado con la comunidad universitaria y el movimiento solidario conllevan construir propuestas de ajuste social, fomentando el desarrollo de habilidades y competencias laborales con la estructura de organizaciones democráticas, en las que se involucren fuerzas productivas mediante la concreción de proyectos y acciones que generen un emprendimiento social y una participación solidaria, conducente a un desarrollo local más alto, organizacional y comunitario. Desde la óptica universitaria y de las organizaciones solidarias, se hace necesario trabajar en un proceso permanente en el cual se evalúen los activos y pasivos sociales y las necesidades existentes e insatisfechas, estableciendo metas y diseñando un redireccionamiento educativo y de actividades, con el objetivo de mejorar la calidad de vida y empresarial, integrando y compatibilizando el medio ambiente y el bienestar social y económico.

Al realizar un breve esbozo de las necesidades no satisfechas de la población, nos encontramos que un nuevo modelo de economía social sería uno de los aspectos clave del desarrollo como fomento y consolidación del espíritu de empresa. El proceso globalizador ha deteriorado de forma progresiva la capacidad de los gobiernos y, sobre todo, de los países en vías de desarrollo, para gestionar la política social, en parte por el proceso de privatización de las áreas de acción que antes eran exclusivas del ejercicio público en frentes cruciales como la prestación de servicios públicos, la salud, la educación y la administración de su propia infraestructura, en la cual la producción y el beneficio pasan a manos del sector privado, cuya racionalidad está determinada no por el interés común sino por la rentabilidad privada.

Este adelgazamiento del Estado no es el producto del desarrollo histórico, sino un acuerdo estructurado a partir del Consenso de Washington, en el que los países se comprometen en el largo plazo a garantizar el equilibrio y el ajuste fiscal. Con este acuerdo se le da fin a los propósitos más fundamentales concebidos para los Estados modernos en el frente de la política social. En este contexto es claro que el logro de objetivos comunes o de carácter público pierde prioridad y pasa a ser responsabilidad de la comunidad civil, organizada a través de diferentes tipos de organizaciones.

En este sentido, la economía social desempeña un papel preponderante en la consecución del crecimiento del capital social, en la medida en que la cultura de la producción solidaria posibilite, mediante procesos participativos de diálogo, la concertación entre el Estado y la Sociedad Civil, la construcción de identidades rotas por la situación de conflictos internos y la formación de un amplio componente de cooperación y ayuda mutua. La formación en economía solidaria en una comunidad como la colombiana, con evidentes problemáticas socioeconómicas que generan desempleo, informalidad, desplazamientos forzosos, ausentismo escolar y violencia social, conduce a cuestionamientos como: ¿cómo generar productividad con equidad? y ¿cómo construir cambio social en las regiones?

La falta de oportunidades y alternativas laborales llevan a una desocupación que incide en los niveles de miseria e indigencia de la población, por lo que se observa especialmente en los países en vías de desarrollo un aumento del trabajo infantil, deserción de la juventud en la educación y el bajo nivel de ésta en la niñez de escasos recursos. Igualmente, la desocupación genera un alto índice de fuga de "cerebros", que se ve reflejado, en la mayoría de los casos, en la baja productividad y competitividad de las empresas. Asimismo, factores como el alcoholismo, la drogadicción y la intolerancia, generadores de la violencia intrafamiliar, la cual trasciende a una violencia social, son productos de esta problemática socioeconómica (ver gráfico 1). 


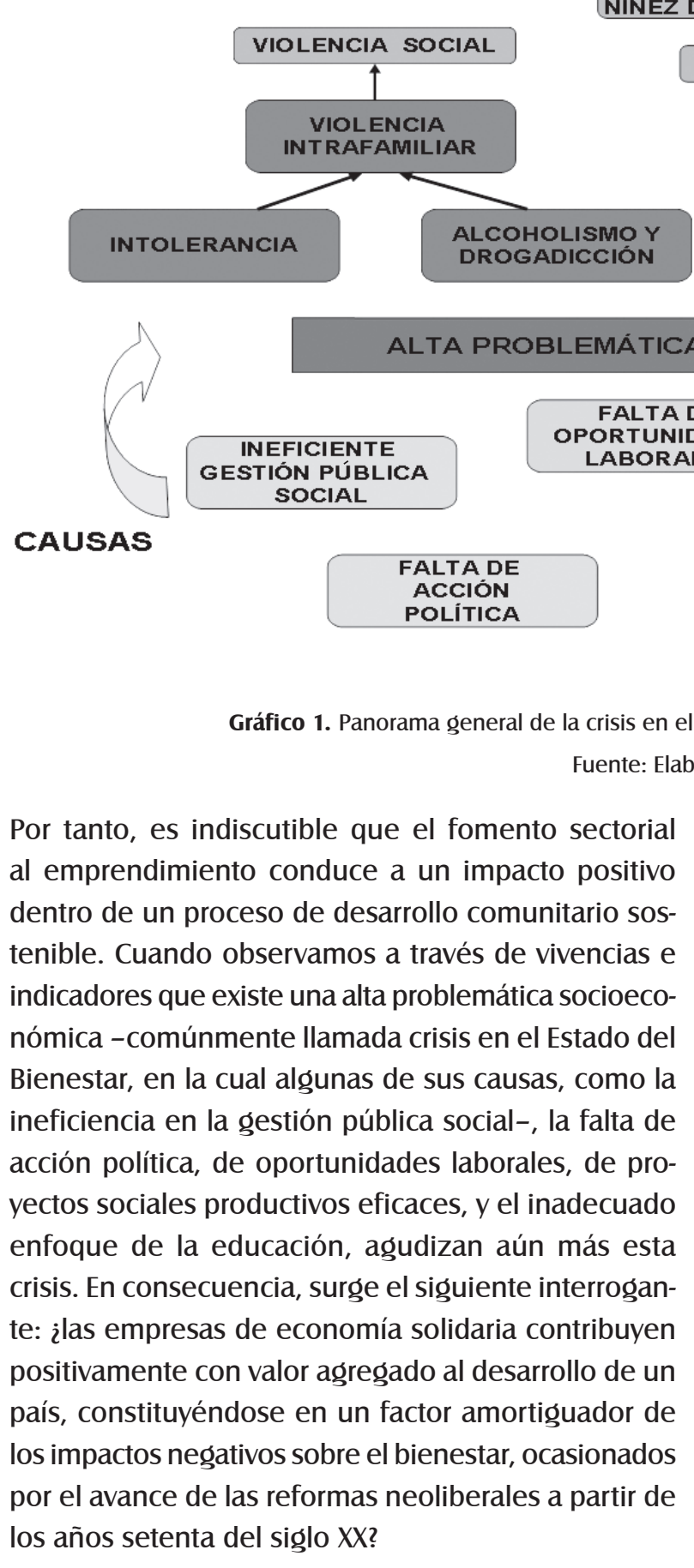

Algunos autores (Senge, 1994 y Maturana, 1998) aducen que el espíritu empresarial y la competitividad descansan sobre aspectos de la conducta humana, tendentes a la búsqueda de las soluciones colectivas, que permitan la construcción de nuevos modelos de desarrollo basados en los principios y valores filantrópicos y de ayuda mutua. Las organizaciones se constituye en el eje central de las articulaciones hacia la constitución de redes empresariales para la generación de diversos mecanismos que integren económica y socialmente sectores productivos y no productivos en los ámbitos en los que poseen mayores ventajas competitivas, para así lograr construir una sociedad más justa y equitativa.

Asimismo, y con base en la Teoría de Capacidad (Sen, 1996), el éxito del funcionamiento colectivo como instrumento de desarrollo y competitividad empresarial está dado en un arreglo social, de acuerdo con los logros y las capacidades particulares de cada individuo, las cuales propone el autor desde dos perspectivas. Primero, el logro de bienestar para un individuo de acuerdo con el resultado alcanzado en su funcionamiento; segundo, la libertad, concebida como las oportunidades reales que la persona requiere para 
alcanzar dicho bienestar, teniendo en cuenta sus capacidades.

Las diferentes modalidades de acción conjunta e integración solidaria en la economía destacan al sujeto colectivo y al uso compartido del conocimiento y las capacidades para el trabajo en equipo, consolidando procesos de "empresarialidad" social y generando nuevas conductas en los individuos. Entonces, es importante el manejo de la conflictividad social mediante la integración ideológica y filosófica, a partir de unos principios y valores mutuos. Para las organizaciones solidarias, los asociados son la razón de ser participando en los roles que les corresponden como usuarios, inversionistas y gestores propietarios. Por esta razón, es importante el análisis de los principios y valores que inspiran la actuación en la gestión de las empresas solidarias.

Para acercarnos a la percepción que los estudiantes, futuros dirigentes o empresarios, tienen acerca de los principios prioritarios en la sociedad, se hace alusión a un estudio ${ }^{3}$ realizado entre 2005 y 2006, dirigido a universitarios de carreras económicas y empresariales en el Valle del Cauca, Colombia, en el que se les formula, entre otras, una pregunta referente a principios con seis opciones, para que fuese valorada de 1 a 6 en orden de menor a mayor importancia. Asimismo, se optó por ofrecer una lista de diez valores y solicitar a los encuestados que otorgaran a cada uno de ellos una calificación de 1 (valoración mínima) a 10 (valoración máxima).

En las tablas 1 y 2 se observa que los estudiantes universitarios entrevistados no son indiferentes a lo que sucede en su entorno. En relación con el principio de libertad, se deja entrever que un $28 \%$ de los encuestados lo consideran de mínima valoración, lo que resulta sorprendente por la edad de los entrevistados. No obstante, hay que resaltar que el $24,6 \%$ le otorga la máxima valoración, lo que contribuye a lograr un $52,7 \%$ de valoraciones entre 4 y 6 para el principio de libertad. Asimismo, debemos hacer énfasis en que es en términos de porcentaje el principio que obtiene el mayor valor, puesto que ese $24,6 \%$ supera al siguiente, $22,8 \%$, correspondiente a la participación democrática. Si consideramos las valoraciones medias, el principio de libertad alcanza un 3,52\%, mientras el 3,87\% obtenido por el principio de igualdad es el valor más alto, lo que lleva a concluir que la igualdad es el principio social más importante para estos jóvenes. En general, al analizar la tabla 1 se puede a afirmar que se tiene la claridad suficiente sobre la facultad para poder decir "sí" o "no", poder compartir y elegir de acuerdo con su bienestar, respetar y hacer valer sus derechos.

Tabla 1. Valoración de principios

\begin{tabular}{|c|c|c|c|c|c|}
\hline Principios & $\begin{array}{c}\text { Calificación } \\
\text { máxima } \\
\mathbf{( 6 )}\end{array}$ & $\begin{array}{c}\text { Calificación mínima } \\
\mathbf{( \% )}\end{array}$ & $\begin{array}{c}\text { Valor con mayor } \\
\text { frecuencia }\end{array}$ & $\begin{array}{c}\text { Valor con menor } \\
\text { frecuencia }\end{array}$ & $\begin{array}{c}\text { valoración media } \\
\text { ponderada }\end{array}$ \\
\hline Libertad & 24,6 & 28,1 & 1 & 3 & 3,52 \\
\hline Solidaridad & 20,2 & 13,2 & 3 & 1 & 3,83 \\
\hline Igualdad & 15,8 & 6,1 & 2 & 6 & 3,87 \\
\hline Justicia & 12,2 & 13,0 & 2 & 4 & 3,30 \\
\hline Respons. S. & 18,4 & 12,3 & 1 & 4 & 3,50 \\
\hline P. Democrática & 22,8 & 23,7 & 4 & 3,41 \\
\hline
\end{tabular}

Fuente: Elaboración propia

3 Osorio, Lourdes - 2007. Tesis Doctoral Las Empresas de Economía Social. Su Papel en la Redefinición de Estado del Bienestar: Lecciones a partir de la Experiencia en el Valle del Cauca - Colombia. Capítulo IV. 
En cuanto a los valores a los que hace referencia el estudio, éstos son de gran importancia para el sector solidario y forman parte de su ideología fundamental, en la medida en que se realiza una valoración del hombre como ser humano, responsable de sí mismo, y teniendo en consideración a las personas que se encuentran en su entorno, aceptando que se debe respeto y confianza hacia los demás individuos que conforman la sociedad. Los valores que fundamentan la cooperación se encuentran enmarcados en la declaración sobre identidad cooperativa realizada por la $\mathrm{ACl}$ en el Congreso de Manchester, en septiembre de 1995.

El respeto es considerado por los entrevistados como el valor de mayor importancia, con una valoración media ponderada de 6,77; esto se deriva de que la puntuación 10 es la que alcanza una mayor frecuencia, $25 \%$ (ver tabla 2). Si se agrega a ésta la correspondiente a la puntuación 9 , se obtiene un muy elevado $46,4 \%$. Cabe mencionar que el respeto genera solidaridad y responsabilidad como base fundamental para una convivencia sana.
Asimismo, como resultado del estudio en mención, se afirma que en su mayoría desconocen el entorno de la economía solidaria y la diferencia con el sector público y privado capitalista. La importancia de esto es significativa, puesto que gran parte de ellos no ha recibido formación alguna en la materia. Por tanto, el conocimiento debe servir no sólo para producir y enriquecerse, sino también para fortalecer la pertinencia social y construir futuro regional.

En las circunstancias actuales de los países en desarrollo la economía se desenvuelve en una nueva tendencia de puertas abiertas, en la que es imprescindible entender esta realidad social y económica, y diseñar programas empresariales con un enfoque más estructurado hacia estas nuevas tendencias, en el que el estudiante sea consciente de la realidad socioeconómica en su futuro desarrollo profesional.

Por tanto, la creación de nuevas empresas con una fuerza real común -con una estructura multiplicadora más democrática y justa, sin abogar por una economía total, sino con igual legitimidad, como la capitalista

Tabla 2. Valoración de valores

\begin{tabular}{|c|c|c|c|c|c|}
\hline Valores & $\begin{array}{c}\text { Calificación } \\
\text { máxima } \\
(10) \\
(\%)\end{array}$ & $\begin{array}{c}\text { Calificación } \\
\text { mínima } \\
(1) \\
(\%)\end{array}$ & $\begin{array}{l}\text { Valor con } \\
\text { mayor } \\
\text { frecuencia }\end{array}$ & $\begin{array}{l}\text { Valor con menor } \\
\text { frecuencia }\end{array}$ & $\begin{array}{c}\text { valoración media } \\
\text { ponderada }\end{array}$ \\
\hline Responsabilidad & 13,4 & 9,8 & 8 & 2 & 6,35 \\
\hline Vocación de Servicio & 5,4 & 13,5 & 4 & $9 / 10$ & 5,04 \\
\hline Autoayuda & 4,5 & 19,8 & 1 & $9 / 10$ & 4,34 \\
\hline Equidad & 9,0 & 9,0 & 7 & 4 & 5,79 \\
\hline Democracia & 23,2 & 6,3 & 10 & $4 / 7$ & 6,54 \\
\hline Tolerancia & 12,5 & 3,6 & 5 & 1 & 6,09 \\
\hline Respeto & 25,0 & 8,0 & 10 & 6 & 6,77 \\
\hline Fidelidad & 3,6 & 10,8 & 6 & $9 / 10$ & 4,54 \\
\hline Satisfacción familiar & 8,1 & 9,9 & $2 / 3$ & 8 & 5,02 \\
\hline Éticos y morales & 9,9 & 7,3 & $4 / 8$ & $1 / 6$ & 5,5 \\
\hline
\end{tabular}

Fuente: Elaboración propia 
y la compartida con la economía estatal, conducente hacia el desarrollo socioeconómico de las regionescasi obliga a que la formación y el conocimiento en economía social o solidaria de los estudiantes de carreras económicas y empresariales, principalmente, deban ser de unas características flexibles no sólo con la capacidad de adaptarse, sino también de prepararse para enfrentar los cambios permanentes, tanto tecnológicos como organizacionales. Es imprescindible entender la realidad social y económica del entorno de cada país o región, y diseñar programas empresariales con un enfoque más estructurado, en el que el estudiante sea consciente de la realidad socioeconómica en su futuro desarrollo profesional.

\section{Desarrollo del espíritu empresarial en el sector solidario}

En el proceso de globalización, las empresas de economía solidaria podrían impulsar la cooperación a través del emprendimiento de cadenas productivas, teniendo en cuenta que su enfoque solidario permite aprovechar múltiples posibilidades de crear empresas en diferentes actividades productivas, como una red organizacional multidisciplinaria, lo que permite reducir costos de operación, comercialización y desarrollo tecnológico; ser autosuficientes en la construcción de bienestar social y de alternativas de mejoramiento económico, reducir los flagelos que se convierten en barreras de crecimiento, y fomentar acciones emprendedoras.

La búsqueda de alternativas de mejoramiento social y económico fomenta, a su vez, acciones emprendedoras, articuladas en temas de desarrollo social y económico que trabajen desde la transformación de la base productiva hasta la comercialización, el fortalecimiento de la autosubsistencia, y que creen nuevos procesos para impulsar el desarrollo humano y el crecimiento económico. El talento humano universitario tiene la idoneidad necesaria para volver una idea de negocio en una realidad como proyecto de vida en una comunidad. Por tanto, poner en marcha un conjunto coherente de orientaciones y procesos, mediante el aprovechamiento de oportunidades y capacidades existentes, provocará nuevos desarrollos e iniciativas productivas; de allí la importancia del emprendimiento como enfoque de desarrollo flexible y participación activa y concertada de la sociedad.

\begin{abstract}
La empresa solidaria como sistema de organización social y económica, alternativa a la organización capitalista de las actividades mercantiles, que fomenta los valores del hombre como ser social y utiliza la fuerza de la cooperación como herramienta de superación colectiva, facilita la aportación plena con objetivos de bienestar general. Siendo una economía capaz de entender las necesidades del hombre, comprometida con el desarrollo real de una comunidad, que incorpora la participación de los sujetos y de los factores productivos y económicos, además, busca aunar fuerzas sociales identificadas por un grupo de entidades constituidas de manera democrática y voluntaria, administradas por sus socios (propietarios), desarrollando actividades sociales o económicas para el beneficio de todos los integrantes de la colectividad empresarial (Pineda, 2000, p. 8).
\end{abstract}

Existen iniciativas con respecto a esta unión de fuerzas sociales en algunos países. Al respecto, se puede citar el caso de España, que cuenta con casos exitosos de emprendimiento social y solidario, entre ellos la Cooperativa Calima en Cádiz, que presta servicios integrales en gestión medioambiental y ha sido galardonada con el premio de excelencia a la mejor experiencia emprendedora juvenil; la Cooperativa el Roble, constituida hace seis años por jóvenes emprendedores y que se encarga de prestar asistencia a personas de la tercera edad, y ha sido galardonada con el premio a la excelencia de emprendimiento en Andalucía por liderazgo empresarial pymes; la Cooperativa Algaba, que trabaja en actividades agroforestales, como la producción de miel, corcho, ganadería ecológica y cría de caballos, y también ha sido premiada como mejor iniciativa emprendedora; y la Cooperativa Hojiblanca (Sociedad Cooperativa Oleícola Hojiblanca) concentra 
su oferta comercializando conjuntamente el aceite de oliva virgen. En un momento en que el mercado estaba atomizado y era local, decidieron unirse y hoy día son la mayor productora de acerita del mundo con $88.000 \mathrm{t}$, y la segunda en aceituna de mesa (35.000 t). Está formada por 45 cooperativas y 25.000 agricultores, ubicados en 37 municipios, y en 1987, se convirtió en organismo de segundo grado.

En Argentina, por citar algunos ejemplos de emprendimiento comunitario entre los existentes de este país, está el de la Cooperativa Educacional Olga Cossettini, en la cual un grupo de familias en Capilla del Monte, provincia de Córdoba, se unieron en una propuesta social educativa, Ilamada Sistema Innovador Banco de Horas Comunitario, que fue galardonado como idea innovadora de emprendedores sociales con el premio Ashoka en el Primer Concurso Nacional de Ideas Innovadoras para Captar Recursos. Otro caso, pero en otro país, es la Unión y Solidaridad de las Cooperativas y Emprendimientos de Economía Social do Brasil (Unisol-Brasil), que es una entidad creada en 2004 para representar y congregar emprendimientos en economía solidaria de diversos sectores productivos. Asimismo, en el Norte de Marruecos se creó el Centro de Estudios Cooperativos para el Desarrollo Local (Cecodel). En el Salvador, la Asociación de Proyectos Comunitarios (Procomes) se creó para fomentar y apoyar iniciativas económicas empresariales con acciones encaminadas a fortalecer la participación social.

En Colombia, se cuenta con cantidad de casos de emprendimiento social, en los que la creatividad frente a las diferentes crisis económicas impulsa una estructura social dinámica de adaptación al cambio. Por ejemplo, la empresa lechera más grande de Colombia, la Cooperativa Colanta, ha sido galardonada con la Cruz de Boyacá, como máximo reconocimiento al cooperativismo rural. Esta cooperativa ha fortalecido al campesinado en diferentes regiones del país, y además de la leche, tiene otras actividades complementarias, como diferentes cultivos y el ganado de carne. Otro caso reciente, pero interesante, es el convenio entre la Pontificia Universidad Javeriana, el Instituto de Estudios Rurales (IER) y diferentes sectores del municipio de Guadalupe, el cual trabaja conjuntamente el Proyecto de Educación Cooperativa de Ahorro y Crédito Agropecuaria Guadalupe Ltda., que está enfocado al acopio lechero y al ecoturismo, en el que participan el sector de transporte, artesanos, productores, hoteles y restaurantes, entre otros, con el objetivo de brindar soluciones a problemas rurales sostenibles y fortalecer la capacidad empresarial solidaria.

Por tanto, mejorar la productividad mediante una mayor preparación del talento humano en las poblaciones más vulnerables, y formular políticas y programas que incentiven su formación laboral y su inserción social y económica constituyen para los instituciones educativas un reto importante y determinante en su responsabilidad social; por ello es necesario profundizar en el valor de la solidaridad, el cual permite la participación tanto de hombres como de mujeres que se encuentran marginados del mercado de trabajo, organizándose productivamente y generando bienes y servicios, como sucede en la actualidad con los pequeños productores, asalariados o informales, que se agrupan alrededor de los fondos rotatorios, a fin de acceder a líneas de fomento a bajo costo, mediante el esquema de emprendimiento solidario.

Es pertinente analizar las distintas dimensiones -sociales, económicas, ambientales y políticas- que surgen de este emprendimiento solidario y que son claves a la hora de abordar verdaderos procesos de cambios sociales con las comunidades, en medio de un entorno globalizado que impone la obligación de crear mecanismos a través de la educación y el fomento de mejores valores y el sentido de pertenencia, especialmente entre los jóvenes.

\section{Proceso alternativo de desarrollo comunitario}

Entonces, podemos preguntarnos de qué manera el aprendizaje colectivo y el desarrollo del capital huma- 
no conducen a una transformación de educación productiva en beneficio de una comunidad. La empresa, como organización social, basa sus resultados en su funcionamiento colectivo, lo cual permite impulsar el aprendizaje en ella, siempre y cuando persista el compromiso hacia nuevos retos, según la realidad social. En opinión de Maturana (1998), las empresas basan su funcionamiento en la emoción del compromiso de las personas, las cuales son parte de la sociedad y, por tanto, determinan a la empresa como organización social en la cual el aprendizaje o la capacidad de los individuos se ve reflejado en sus acciones.

El sentido de pertenencia, la responsabilidad social, la iniciativa, la autoexigencia y el compromiso hacia la construcción del tejido social de todos los miembros de la organización los comprometen y responsabilizan con ésta, forjando a cada uno de los individuos que la componen con capacidad para tomar decisiones, crear y aprender. Es por esto que la empresa debe valorar y aprovechar los conocimientos de su capital humano, sus capacidades, formación, valores, proyecciones y demás cualidades que le permitan fortalecerse. De esta manera, y tomando en cuenta a Senge (1994), la organización puede desarrollar un modelo de emprendimiento que impulse el aprendizaje de sus miembros e implique el desarrollo de habilidades para responder a los constantes cambios, alcanzando mayor competitividad en una realidad cada vez más diversa y pluralista.

En el gráfico 2 se pretende mostrar un proceso alternativo de desarrollo comunitario en cual se involucran actividades sectoriales y económicas desde la trihélice
Academia - Sistema Empresarial - Estado, cuya base fundamental del proceso por ser seres sociales, es el talento humano. Éste se debe formar y preparar adecuadamente, bajo el esquema de valores, conocimientos, proyección empresarial productiva y social, y con una visión o proyección de desarrollo local y regional, innovación productiva y pertinencia social, con el propósito de que pueda participar en la formulación de programas y políticas que incentiven su inserción social y económica, generando, asimismo, emprendimiento.

Dicho emprendimiento estará fundamentado en el espíritu empresarial, en el cual la persona sienta hacer empresa, produzca, acumule y amplíe un nuevo factor económico sin ser excluyente. La combinación del conocimiento sobre el modelo de mercado capitalista o el prototipo solidario, en el cual el capital humano, es decir, sus asociados o empleados que pertenecen e integran el patrimonio según los bienes y derechos de la sociedad, sean reconocidos como un verdadero activo social (Acs), y de esta manera, visualizar el patrimonio social ( $P$ = Acs - Ps) como la sumatoria de riquezas y derechos de los asociados, y que representa la inversión realizada por las organizaciones innovadoras y productivas conducentes a incrementar el grado de bienestar de sus asociados y su entorno como aporte a la disminución del pasivo social (Ps) creado por las necesidades básicas insatisfechas de la comunidad, las obligaciones y compromisos del Estado, de la sociedad y sus instituciones para con ésta. Así a mayores asociados y autogestionamiento, menores necesidades insatisfechas: $(\mathrm{AC}=\mathrm{P}-\mathrm{Ps})$. 


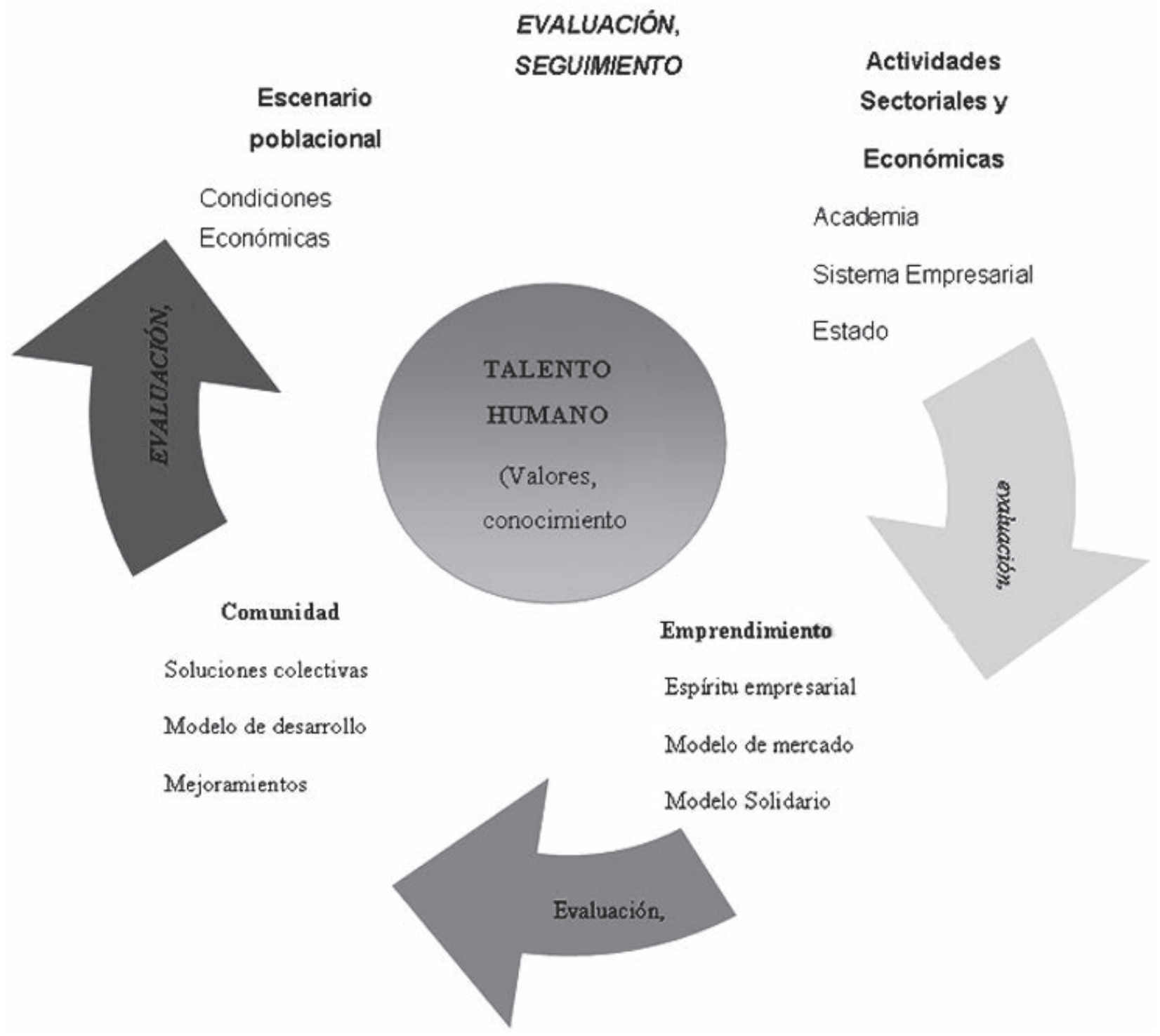

Gráfico 2. Proceso alternativo de desarrollo comunitario. Fuente: elaboración propia.

Sin embargo, para que lo anterior cumpla su objetivo, se hace necesario contar con una comunidad participativa y organizada que genere soluciones colectivas, sociales y productivas a partir de un modelo de desarrollo y mejoramiento del bienestar social en el que la empresa capitalista y el Estado no llegan o lo hacen de manera insuficiente. También es preciso que entre los sectores educativo, productivo y gubernamental se realice la capacitación y formación acertada, por la cual se generan cambios paulatinos de mayor com- promiso social, capaz de utilizar el conocimiento hacia el sistema empresarial en la generación de nuevas empresas, la innovación y las oportunidades laborales y de mejor calidad.

Para que exista una verdadera sinergia en el proceso de desarrollo es necesario que durante todo el proceso y, de forma colectiva, se realice una constante evaluación, seguimiento y acompañamiento práctico en busca de soluciones sociales y económicas; se 
creen nuevos espacios con las condiciones de nuevo conocimiento y desarrollo empresarial competitivo, mediante el aprovechamiento de la habilidad del talento humano capaz de responder a los cambios socioeconómicos reales. Es allí donde las Instituciones de Educación Superior (IES) y las empresas ya constituidas desempeñan un papel importante, contribuyendo a construir ese escenario poblacional y a aumentar la competencia laboral con mejores condiciones sociales y económicas.

\section{El papel del sector educativo en el desarrollo del espíritu empresarial en el contexto universitario}

En este apartado, siguiendo a Max Neef (2004), queremos reflexionar acerca del reto que la institución universitaria tiene en la actualidad, como agente activo en los procesos de desarrollo regional y bienestar social.

\section{Desafío del sector educativo en los procesos sociales}

En un contexto como el colombiano, el interés homogeneizador de la globalización constituye una amenaza y, en consecuencia, impone la obligación de crear mecanismos a través de la educación, la formación de valores y la pertenencia, que permitan resistir los fuertes cambios en medio de problemas estructurales como la fase de estancamiento industrial, de marcadas desigualdades en el nivel de desarrollo y de continuidad en los planes nacionales, en virtud de los cambios de las políticas macroeconómicas, el bajo crecimiento del empleo, las altas tasas de desempleo, el escaso poder adquisitivo y la reestructuración del tejido social, económico y productivo, que conllevan la pobreza, la indigencia y procesos migratorios, especialmente del campo hacia la ciudad, entre otros. Es tal el desafío del sector educativo en los procesos sociales, que el empleo y su calidad están relacionados con el nivel de educación.

Los acontecimientos políticos y socioeconómicos de América Latina en las últimas cuatro décadas hacen entrever el desmejoramiento en muchos índices de vida (ver tablas 3,4 y 5), por lo que evidencia cada vez más ingresos bajos, ausencia de equidad en la distribución de la riqueza, desempleo creciente (pasa del $6 \%$ en los años setenta al $10 \%$ en los años noventa), aumento de la informalidad, aumento del número de pobres e indigentes, salarios inestables, baja en la demanda de trabajadores poco cualificados, debido a la acelerada y sucesiva revolución tecnológica, entre otros.

Tabla 3. Crecimiento económico e inflación

\begin{tabular}{|c|c|c|c|c|c|c|c|c|}
\hline \multirow{2}{*}{ País } & \multicolumn{4}{|c|}{$\begin{array}{c}\text { Inflación } \\
\text { (Tasa de variación anual) }\end{array}$} & \multicolumn{4}{|c|}{$\begin{array}{c}\text { Crecimiento PIB } \\
\text { (Tasa variación anual) }\end{array}$} \\
\hline & 1991 & 2002 & 2005 & 2006 & Periodos & 2000 & 2005 & 2006 \\
\hline América Latina & $\begin{array}{c}7 \\
(2001)\end{array}$ & 10 & $6,1 / 7$ & $6,0 / 7$ & $\begin{array}{l}5,5(50-80) \\
1,2(81-90) \\
3,3(91-95) \\
3,1(96-00) \\
3,2(91-00)\end{array}$ & $\begin{array}{c}2,0(2000) \\
0,4(2002) / 5 \\
1,5(2003) / 5\end{array}$ & $4,3 / 7$ & $4,1 / 7$ \\
\hline UE-15 & $\begin{array}{c}4,5 \\
(1992)\end{array}$ & $\begin{array}{c}1,5 / 1 \\
(2000) \\
2,3 / 2 \\
(20 w 00) \\
2,4 / 3 \\
(2000) \\
\end{array}$ & $\begin{array}{c}2,2 / 9 \\
(\mathrm{EU}-12)\end{array}$ & $\begin{array}{c}2,1 / 9 \\
(\mathrm{EU}- \\
12)\end{array}$ & $\begin{array}{c}2,3(50-73) \\
1,9(74-98) \\
-1,0(91-93) \\
2,6(94-00)\end{array}$ & $\begin{array}{l}0,9(2002) / 4 \\
0,5(2003) / 4\end{array}$ & $\begin{array}{c}1,2 / 9 \\
(E U-12)\end{array}$ & $\begin{array}{c}2,0 / 9 \\
(E U-12)\end{array}$ \\
\hline Estados Unidos & 4,2 & $\begin{array}{c}2,3 / 1 \\
(2000) \\
3,4 / 2 \\
(2000) \\
1,65 / 8\end{array}$ & $\begin{array}{c}2,63 / 8 \\
(2004) \\
2,8 / 9\end{array}$ & $2,4 / 9$ & $\begin{array}{l}3,9(92-00) \\
3,2(93-96) \\
4,5(97-00)\end{array}$ & $\begin{array}{l}5,0(2000) / 2 \\
7,9(2003) / 4\end{array}$ & $3,5 / 9$ & $3,4 / 9$ \\
\hline
\end{tabular}




\begin{tabular}{|c|c|c|c|c|c|c|c|c|}
\hline Japón & 3,3 & $-1,27 / 8$ & $\begin{array}{c}2,11 / 8 \\
(2004) \\
-0,3 / 9\end{array}$ & $\mathrm{n}, \mathrm{d}$, & $\begin{array}{c}9,6(51-70) \\
4,5(71-80) \\
5,0(87-90) \\
1,0(91-00) \\
3,8(1991)\end{array}$ & $\begin{array}{l}1,4(2000) / 2 \\
7,8(2003) / 6\end{array}$ & $2,7 / 9$ & $2,8 / 9$ \\
\hline
\end{tabular}

Fuente: Elaboración propia a partir de Cepal Anuario Estadístico 2002 y 2003, oct. de, 2001, páginas web INE e IEA. Fondo Monetario Internacional (2003). 1/Ocde - Economic Outlook Vo. 70 nov. 2001. 2/FMI - World Economic Outlook oct. 2001, 3/ Eurostat 2003. 4/ BCE, EA, 2003, 5/ Eurostat (2003) Latin Focus, 6/ BOJ, National Bureau of statistics, 2003, 7/ Cepal América Latina y el Caribe Proyecciones 2006-2007(abril del 2006), 8/ Banco Mundial Estadísticas de Inflación por País 2000-2004 valores expresados en porcentaje, 9/Fondo Monetario Internacional, Perspectivas de la economía mundial abril de 2006. Globalización e inflación.

Tabla 4. Economía informal en América Latina (países seleccionados)

\begin{tabular}{|c|c|c|c|}
\hline PAÍS & $\begin{array}{c}\text { POBLACIÓN } \\
\text { (millones) }\end{array}$ & $\%$ del PIB & $\begin{array}{c}\% \text { de la } \\
\text { Fuerza de } \\
\text { Trabajo }\end{array}$ \\
\hline $\begin{array}{c}\text { Argentina } \\
1990 \\
2000 \\
2005 \\
\end{array}$ & $\begin{array}{c}32.527 \\
37.032 \\
36.800 / \mathrm{e} \\
\end{array}$ & $\begin{array}{c}25,0 \\
25.4 / e\end{array}$ & 22,9 la \\
\hline $\begin{array}{l}\text { Brasil } \\
1990 \\
2000 \\
2005 \\
\end{array}$ & $\begin{array}{c}148.030 \\
170.693 \\
177.000 / \mathrm{e}\end{array}$ & $\begin{array}{c}40,0 \\
39.8 / \mathrm{e}\end{array}$ & $\begin{array}{l}40,6 \\
47,1\end{array}$ \\
\hline $\begin{array}{l}\text { Chile } \\
1990 \\
2000 \\
2005 \\
\end{array}$ & $\begin{array}{c}13.100 \\
15.211 \\
15.800 / \mathrm{e}\end{array}$ & $\begin{array}{c}20,0 \\
19.8 / \mathrm{e}\end{array}$ & $\begin{array}{l}37,9 \\
37,5\end{array}$ \\
\hline $\begin{array}{c}\text { Colombia } \\
1990 \\
2000 \\
2005\end{array}$ & $\begin{array}{c}34.970 \\
42.321 \\
44.600 / \mathrm{e}\end{array}$ & $\begin{array}{c}39,0 \\
39.1 / \mathrm{e}\end{array}$ & $\begin{array}{c}45,7 \\
57,0 / b\end{array}$ \\
\hline $\begin{array}{c}\text { Honduras } \\
1990 \\
2000 \\
2005\end{array}$ & $\begin{array}{c}4.879 \\
6.845 \\
7.000 / \mathrm{e}\end{array}$ & $\begin{array}{c}n . d \\
49.6 / e\end{array}$ & $\begin{array}{l}57,6 \\
60,7\end{array}$ \\
\hline $\begin{array}{c}\text { México } \\
1990 \\
2000 \\
2005 \\
\end{array}$ & $\begin{array}{c}83.226 \\
98.881 \\
102.000 / \mathrm{e}\end{array}$ & $\begin{array}{c}30,0 \\
30.1 / e\end{array}$ & $\begin{array}{l}38,4 \\
40,1\end{array}$ \\
\hline $\begin{array}{l}\text { Perú } \\
1990 \\
2000 \\
2005 \\
\end{array}$ & $\begin{array}{c}21.753 \\
25.939 \\
27.100 / e\end{array}$ & $\begin{array}{c}60,0 \\
59.9 / e\end{array}$ & $\begin{array}{l}52,7 \\
53,7\end{array}$ \\
\hline $\begin{array}{c}\text { Venezuela } \\
1990 \\
2000 \\
2005 \\
\end{array}$ & $\begin{array}{c}19.502 \\
24.170 \\
25.700 / e\end{array}$ & $\begin{array}{c}33,0 \\
33.6 / \mathrm{e}\end{array}$ & $\begin{array}{l}38.6 \\
49.1\end{array}$ \\
\hline $\begin{array}{c}\text { América } \\
\text { Latina } \\
1970 \\
1980 \\
1990 \\
2000 \\
2005 \\
\end{array}$ & $\begin{array}{c}357.265 \\
436.022 \\
514.692 \\
\text { n.d. }\end{array}$ & $\begin{array}{l}35,2 / \mathrm{c} \\
41.5 / \mathrm{e}^{\star}\end{array}$ & $\begin{array}{c}42,8 \\
46,4 \\
56,0 \\
46.9 / d\end{array}$ \\
\hline
\end{tabular}

Fuente: Elaboración propia a partir de Cepal -Boletín Demográfico diferentes años. Dane-Colombia (2004), OIT -Panorama LaboralDiferentes años. a/ Trabajadores por cuenta propia 1999. No se incluye servicio doméstico. b/ 2003. c/ Promedio no ponderado de los países seleccionados año $2000 \mathrm{~d} /$ OIT - Panorama laboral 2005. América Latina y el Caribe. Avance primer semestre. e/ Banco Mundial, Corporación financiera mundial. Características de la economía, *América Latina y el Caribe, http: //espanol.doingbusiness.org/ ExploreEconomies/EconomyCharacteristics.aspx?direction=ascysort=5. 
Tabla 5. Tendencia mundial de la desigualdad del ingreso, 1975-1995 (en porcentajes de población)

\begin{tabular}{|c|c|c|c|c|}
\hline Grupos de países & $\begin{array}{c}\text { Desigualdad } \\
\text { Creciente }\end{array}$ & Desigualdad Estable & Desigualdad Decreciente & $\begin{array}{c}\text { Tendencia no } \\
\text { identificable }\end{array}$ \\
\hline Países industrializados & 71,8 & 1,2 & 27,0 & 0,0 \\
\hline Europa Oriental & 98,1 & 0,0 & 0,0 & 1,9 \\
\hline Ex Unión Soviética & 100,0 & 0,0 & 0,0 & 0,0 \\
\hline América Latina & 83,8 & 0,0 & 11,4 & 4,8 \\
\hline Sur de Asia y Medio Oriente & 1,4 & 70,2 & 14,4 & 14,0 \\
\hline Asia del Este & 79,4 & 4,4 & 16,1 & 0,1 \\
\hline África & 31,6 & 11,9 & 7,7 & 48,8 \\
\hline Mundo & 56,6 & 22,1 & 15,6 & 5,7 \\
\hline
\end{tabular}

Fuente: Cepal, 2002, Visión Global. Cap. 4

La integración de la comunidad académica y el movimiento solidario conducen a construir propuestas de ajuste social, fomentando el desarrollo de habilidades y competencias laborales a partir de la estructura de organizaciones democráticas. Según Max Neff (2004), la educación superior debe tender a la integración de las instituciones, las empresas y la comunidad. Esta acción conjunta de agentes públicos y privados implicará, muy seguramente, adecuar los conocimientos, el saber hacer empresarial y la competencia laboral a las condiciones que impone el mercado en la actualidad.

\section{Alternativa institucional generadora de desarrollo}

La universidad nace de un anhelo de humanizar y difundir los conocimientos; con el tiempo se convierte en una fuerza integradora, organizadora e intercomunicadora, productora de nuevas tendencias, forjadora y generadora de desarrollo científico; es por ello que se consolida como eje central y fundamental para integrar la cultura con el conocimiento científico en los procesos de formación y producción.

La formación del talento humano dentro del contexto socio-empresarial, posibilita y orienta la realización de proyectos de vida, aprendizaje colectivo, apropiación social, transformación productiva y construcción de estructuras de pensamiento, más que a la transmisión de información y conocimiento. El enfoque en las áreas económicas y empresariales es necesario para que la concepción que el hombre tiene sobre sí mismo y sobre su entorno y de la problemática actual enmarcada en el modelo neoliberal que se enseña en las diferentes instituciones académicas sea verdaderamente instruido como tal, analizado y comparado con los demás modelos económicos. De forma tal, que conduzca al futuro profesional empresarial hacia un verdadero juicio de la economía mundial. Es importante también, desarrollar, promover y fomentar un componente que conduzca hacia la cultura de la creatividad empresarial transformadora y productiva, e identifique el potencial del capital humano, que agregue valor, cree y accione procesos productivos bajo el esquema de la responsabilidad social empresarial y construcción social.

Por ello, es el momento apropiado para que las instituciones universitarias del país planteen la formación y el desarrollo del ser humano -hoy estudiante, mañana, empresario, científico o gobernante de una comunidad o nación- de manera objetiva, consciente del juego económico en el que se encuentra inmersa la humanidad actualmente. La academia debe conducir a sus estudiantes a la originalidad, la creatividad y el desarrollo de la capacidad innovadora, y cultivar la sensibilidad hacia las tendencias socioeconómicas manifestadas, proponiendo un modelo de organización alternativo, democrático y participativo ante el modelo capitalista de mercado, en el que se conduzca a la creación y no sólo a la búsqueda de empleo, y en el cual cada individuo sea considerado como pro- 
ponente de desarrollo alternativo y capital social de la organización.

En abril de 2007 se celebró el Foro Económico Mundial en Chile, Ilamado Consenso de Santiago, en el cual se afirmó que la desigualdad social y económica es el principal riesgo de los países latinoamericanos, y que uno de los motores para superar este flagelo es la democratización de una educación con calidad, sin perder el foco en el proceso de liberalización económica.

\section{Papel de la universidad}

La vida profesional y el emprendimiento, como proyección de vida y transformación social positiva, comprometen el papel de la universidad a brindar mayores oportunidades legítimas para la persona que se está formando. Como lo señala el Vicerrector de investigaciones y Doctorados de la Universidad de los Andes, José Villaveces, "hoy las universidades sólo pueden pensarse asumiendo las tres funciones de 1) transmitir el conocimiento producido por los demás, 2) producir conocimiento propio sobre la realidad inmediata y 3 ) enseñar a producir conocimiento propio" (2007, pp. 24-26), tareas que deben ser desarrolladas entre el área de investigación y docencia como un factor determinante en la consolidación de una comunidad académica y su misión social y económica. Por tanto, los siguientes interrogantes cuestionan las actuales formas trascendentales del quehacer diario formativo:

- ¿Para qué se está formando al joven o futuro profesional?

- ¿Qué valor tienen la familia y el entorno para él?

- ¿Qué le puede aportar a la sociedad?

- ¿Qué planes, metas, proyectos u objetivos proyecta?

- ¿Qué piensa hacer cuando termine sus estudios, qué alternativas de trabajo se han mostrado?
- ¿La institución educativa sólo piensa en que los egresados Ilenen hojas de vida o generan el emprendimiento por medio de las Spin-off o incubadoras?

- ¿Cuáles son las oportunidades y alternativas que se está brindando y mostrando al futuro profesional desde la academia para que desarrolle su proyecto de vida laboral?

Entonces, la universidad desempeña un papel fundamental en todo este proceso de formación comunitaria y empresarial, pues inicia una enseñanza hacia el cambio, que permita al estudiantado fortalecer $y$ organizar su manera de pensar y actuar, tanto en lo social como en lo cultural, enriquecerá su conocimiento y le permitirá crear y analizar objetivamente su contexto actual, así como impartir las materias impuestas legalmente, promoviendo una cultura investigadora que permita crear transformaciones de forma sinérgica con las demás instituciones, el gobierno y la comunidad. Los acercamientos y la puesta en práctica de sus manifestaciones en una realidad social y educativa podrá, posiblemente, disminuir los desacuerdos, la desorientación y el sinnúmero de problemas sociales existentes en el país e incentivar hacía el trabajo solidario, en el que el profesional sea capaz de abanderar un desarrollo integral, ligado al crecimiento económico, al bienestar social y natural, forjando un ideal en el cual la vida prime sobre cualquier otro interés.

Es necesario que todos aporten para crear una comunidad integral, más humana y con el poder de incitar a otras instituciones hacia el verdadero cambio que nos compete. El sector solidario colombiano, en busca de generar estrategias dirigidas a amortiguar efectos negativos en los elementos del Estado del bienestar, sentidos con mayor fuerza a partir de la década del ochenta en la mayoría de los países de América Latina, desarrolla capacidades productivas en diferentes sectores, como la salud, la educación, el desarrollo rural, la recreación con perspectivas de empleo y capacitación, entre otros, ya sea mediante el desarrollo empresarial participativo como red mul- 
tidisciplinaria y organizacional, a partir de procesos que contribuyan a la generación de conocimiento, innovación y desarrollo, o a través de la figura de unidades productivas de diversas actividades, hacer presencia en cada uno de los eslabones de la cadena de un sector productivo determinado, de acuerdo con las apuestas regionales. Precisamente, es aquí donde la universidad, como centro de formación, desempeña un papel trascendental: fomentar la economía solidaria y los conocimientos apropiados de una fuerza capaz de entender las necesidades del ser humano, comprometida con el desarrollo real de una comunidad, que incorpora la participación de los sujetos y de los factores productivos dentro de un compromiso social en ambientes participativos.

Hoy en día es evidente el interés de la academia en diferentes países por contribuir a la profesionalización del sector social o solidario como polo de desarrollo. Se pueden analizar los espacios que ha ganado, especialmente en los últimos años, como una alternativa de desarrollo y bienestar social, razón por la cual se han implementado a nivel de posgrado y pregrado cátedras o áreas de conocimiento sobre economía social o solidaria, lo que implica sustentar la necesidad, importancia y pertinencia de contar con investigaciones, textos y profesores dispuestos a generar conocimiento en torno a esta temática, que permitan coadyuvar a la formación integral de los futuros profesionales, en quienes la economía social puede representar oportunidades de desarrollo social e integral, empleo y emprendimiento.

Por citar algunos casos: en Colombia, la Pontificia Universidad Javeriana cuenta en el posgrado de Administración con una Especialización en Gestión de Empresas del Sector Solidario y con el Centro de Investigación de Economía Solidaria (CIES); la Universidad Autónoma de Occidente realiza un estudio para ofrecer una especialización en Economía Solidaria, y además, cuenta con una línea de investigación en el tema; la Universidad Santiago de Cali tiene en su pregrado de Economía la cátedra de Economía Solidaria. En Argentina, la Facultad de Derecho y Ciencias
Económicas de la Universidad de Buenos Aires ofrece cursos para fortalecer la cultura emprendedora y generar creatividad frente a la crisis social, con una estructura dinámica de adaptación al cambio, basados en estatutos sociales y formas organizacionales; por su parte, la Universidad Católica de Córdoba cuenta con la especialización en Gestión de Organizaciones sin Ánimo de Lucro.

También se pueden mencionar diversas redes que se están creando entre diferentes instituciones académicas para desarrollar eventos, seminarios o cursos, como la Maestría en Economía Social como proyecto conjunto (Maes/ICO-UNGS de Argentina) del grupo de investigación sobre economía solidaria de la cátedra Unesco/Unisinos de Río Grande do Sul en Brasil, del Colegio Mexiquense, y de Flacso Ecuador; o la Red Universitaria de Las Américas, en estudios cooperativos y asociativismo (UniRcoop), creada en 1995 por centros de educación superior de Canadá, Centro y Sur América. Asimismo, está la Red de Investigadores Latinoamericanos en Economía Social (Riless), la Red Colombiana Interuniversitaria de Economía Social y Solidaria (Unicosol), en la que se encuentran trabajando sobre el tema cerca de doce universidades del país, y como experiencia de expansión y difusión en la construcción de un verdadero modelo de economía solidaria y además como una de las consecuencias positivas del I Foro Social Mundial en Porto Alegre, realizado en el 2001, se han unido 47 universidades en el Brasil que trabajan en una red nacional en proyectos y promoción sobre el tema, similar a los más de 270 investigadores de cerca de cuarenta universidades españolas trabajando en el desarrollo de la economía social.

Al trasladarnos fuera de Suramérica, se encuentran experiencias como la del Grupo Mondragón en España con la Universidad de Mondragón, que imparte, entre otros, enseñanza ligada a la demanda de profesionales de grupos industriales y empresariales específicos; la Universidad de Barcelona, que ofrece un máster en Economía Social, dirigido a las empresas del sector social, además, cuenta con un Centro 
de Investigación de Economía y Sociedad (CIES); la Universidad Católica de Ávila imparte la asignatura y cuenta con un área de conocimiento en Cooperativismo y Economía Social, e impulsa diversas jornadas y encuentros sobre la temática, como el I Encuentro Iberoamericano de Desarrollo Rural y Economía Social, realizado en 2005, el cual se celebró en Bogotá en 2007. También cabe mencionar dentro de estos pocos ejemplos a Estados Unidos, con The Harvard University Cooperative Society, una de las cooperativas perteneciente a una de las universidades de más prestigio y calidad del mundo, creada en 1882 por un grupo de estudiantes como comunidad académica, hoy en día su misión es proveer servicios y productos de la más alta calidad.

\section{Trabajo conjunto academia, gobierno, comunidad}

Encontrar el equilibrio completo con esfuerzo conjunto para crear emprendimiento, desarrollar y mejorar procesos, ofertar y transferir resultados y capacidades -activos intelectuales- es un compromiso, primero en generación de confianza entre las instituciones de educación superior y el sector productivo (empresas), acompañado de una estructura de interfaz y entendimiento mutuo. La universidad desempeña un papel importante en el desarrollo del entorno, incidiendo directamente en la formación de ciudadanos sociales y en su inserción como empleados o líderes empresariales en una cultura de interrelación entre los diversos sectores y procesos productivos, de acuerdo con las prioridades en las agendas internas regionales. La empresa, junto con la academia, deberá involucrar al Estado, según su agenda de investigación científica y tecnológica, e identificar y absorber los recursos públicos y el uso adecuado de incentivos para la industrialización y la utilidad en la promoción y competitividad del sector productivo regional, como una red eficiente de trabajo conjunto. Por su parte, el gobierno deberá promover la creatividad e incentivar nuevas actividades y procesos que permitan fortalecer la base productiva para adaptarse a los cambios del mercado.
Es necesario que exista un compromiso social real en la cultura académica. La economía solidaria es un modelo útil para mejorar y difundir el conocimiento profesional, generando cambios paulatinos de mayor compromiso social hacia el emprendimiento. Tal emprendimiento puede tener alternativas tanto del modelo capitalista como del solidario, o una combinación de ambos, siempre y cuando se encuentre orientado al entorno laboral de acuerdo con las necesidades del ambiente productivo. En las sociedades contemporáneas, las organizaciones son estructuras dinámicas que evolucionan, $y$ en las cuales las personas tratan de fortalecerse mutuamente para satisfacer sus necesidades básicas.

Como se ha mencionado anteriormente, la creación de nuevas empresas con base en una estructura más democrática y justa es clave para el desarrollo socioeconómico de las regiones donde todos están involucrados: mipymes, estudiantes, profesionales, independientes y Estado. Igualmente, la formación teórica aplicada que involucre contenidos, habilidades y valores a los responsables de la gestión empresarial debe constituirse en un objeto social y económico. El sistema educativo debe promocionar la economía solidaria, fomentar la gestión empresarial productiva y social, aplicar y socializar el conocimiento a partir de la eficiencia de factores como el capital financiero y tecnológico, la gestión, la solidaridad y el saber hacer; asimismo, generar emprendimiento empresarial, es decir, debe estar inmerso en un ambiente en el que se brinden diferentes alternativas empresariales en la enseñanza y la práctica del aprendizaje y el trabajo colectivo, para que haya una verdadera apropiación social, tecnológica y productiva para el beneficio y desarrollo regional (ver gráfico 3).

Las acciones tripartitas emprendedoras permiten motivar a los estudiantes para que creen empresa y organicen redes comunitarias empresariales, acercándose más a la comunidad, para así aprovechar óptimamente los recursos, generando puestos de trabajo y creando riqueza social y económica. Por su parte, el gobierno y la academia pueden realizar 
acciones preventivas o correctivas. El primero debe incentivar y brindar apoyo financiero o tributario a proyectos productivos, por medio de la creación de redes de microcrédito, fondos emprendedores, redes de inversiones, innovación y uso de nuevas tecnologías. La segunda debe preparar a los empresarios, actuales y futuros, para enfrentar la globalización, la política de integración abierta o los diferentes tratados internaciones comerciales ${ }^{4}$. La academia, mediante el voluntariado empresarial, ya sea como apoyo, guía o asesoría, también puede crear semilleros empresariales o centros de emprendimiento con visión de innovación y desarrollo tecnológico, y contribuir con una formación, capacitación, asesoría y acompañamiento con una gestión basada en la eficiencia global.

Gráfico 3. Comunidad, academia y Estado

\section{Comunidad, Academia y Estado}

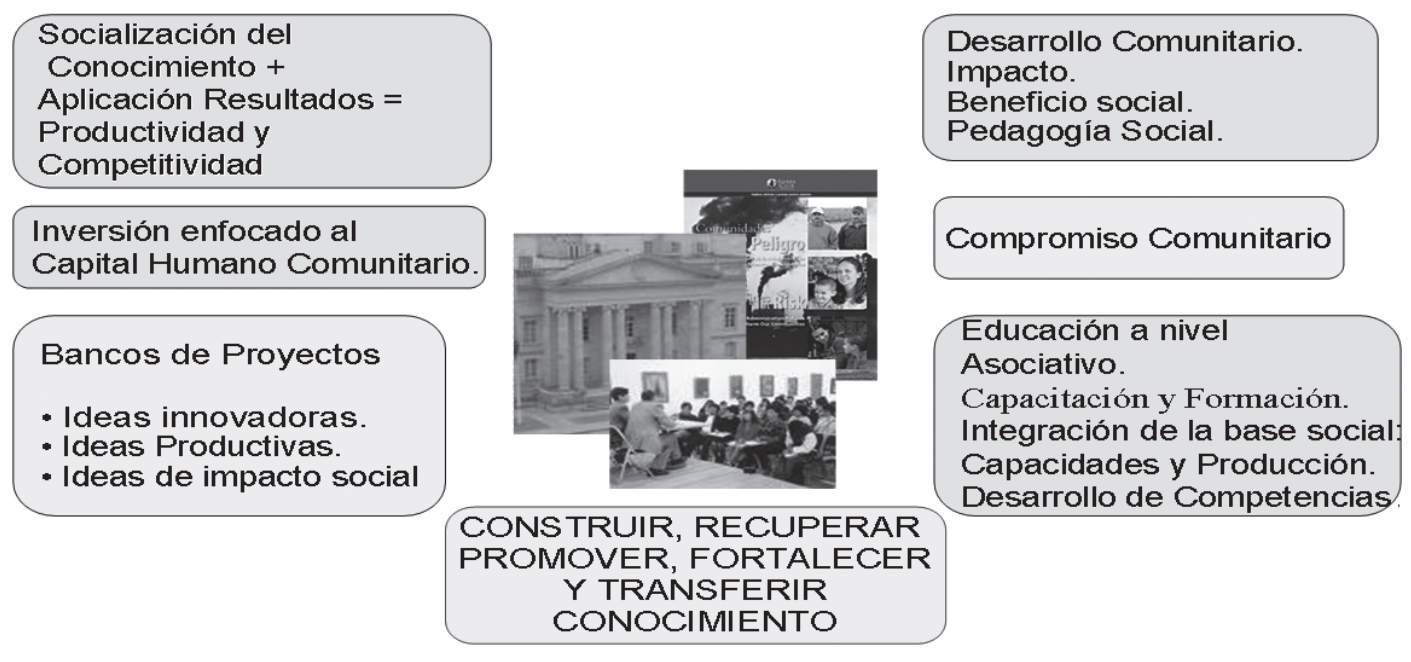

Fuente: elaboración propia

4 Algunos acuerdos comerciales o políticas integracionista que se pueden mencionar son: 1) Aptdea (Andean Trade Preference and Drug Erradication Act) anteriormente ATPA (programa unilateral de preferencias arancelarias a algunos sectores otorgados por Estados Unidos a países andinos -Colombia, Perú, Ecuador y Bolivia). 2) SGP Andino (Sistema Generalizado de Preferencias para países Andinos. Este es un sistema de rebaja del arancel aduanero que otorga la Unión Europea para importaciones provenientes de países andinos). 3) TLC -G3 (Tratado de Libre Comercio entre Colombia, México y Venezuela). 4) TLC (Tratado de Libre Comercio entre Estados Unidos-Colombia y Estados Unidos con otros países. Es de intercambio comercial para mejorar acceso de sus productos). 5) CAN (Comunidad Andina de Naciones. Acuerdo de intercambio comercial entre Colombia, Bolivia, Perú y Ecuador). 6) Aladi (Asociación Latinoamericana de Integración. Acuerdos entre los países de ésta integración económica y convenios de pagos de créditos comerciales). 7) Mercosur (Acuerdo de Complementación Económica. TLC entre Colombia, Venezuela, Ecuador, Argentina, Brasil, Uruguay y Paraguay, para impulsar la libre circulación de bienes y servicios, eliminando restricciones arancelarias). 8) Alca (Área de Libre Comercio para las Américas. Favorece el flujo e inversión comercial entre 34 países de América con una normatividad clara).
El trabajo conjunto de la comunidad empresarial, la academia y el Estado se debe enmarcar en aspectos clave como el aumento de la productividad y la competitividad regional, la inversión enfocada al capital humano comunitario, la integración de la base social, el planteamiento, implementación y evaluación de ideas innovadoras y productivas; todo esto como resultado de la socialización del conocimiento, el desarrollo de capacidades y competencias de la gente, más la aplicación de resultados de investigación. Por tanto, es necesario una educación, capacitación o formación enfocada a construir, recuperar, promover, fortalecer y transferir conocimiento, y conducente a generar desarrollo comunitario, impacto y beneficio social. 


\section{A manera de conclusión. La vida profesional, el emprendimiento y el conocimiento en economía social}

En este artículo se destaca la importancia que se le debe dar al tema del emprendimiento, la formación y la capacitación en economía social, especialmente a las personas en proceso formativo que salen a enfrentar el mercado laboral, el mundo empresarial y el pasivo social, convirtiendo a la economía solidaria en una alternativa de emprendimiento rentable y eficiente mediante un trabajo conjunto entre el sector productivo (empresas), la fuerza laboral en formación (instituciones educativas) y el Estado.

Teniendo en cuenta los fundamentos filosóficos o ideológicos que sustentan el movimiento solidario como base doctrinal en las acciones del sector en el sistema económico, social, político y cultural, los principios y los valores buscan la realización plena de una colectividad con un proyecto de vida en el que se actúe con responsabilidad, compromiso, con sentimiento de pertenencia a la comunidad y hacia la búsqueda del crecimiento personal, el desarrollo social, económico y regional.

No recibir formación alguna en economía solidaria significa el desconocimiento del entorno, la importancia y el aporte de estas empresas de bienestar social; además, cierra las posibilidades a nuevas alternativas concretas de hacer economía con gestión de desarrollo socioeconómico diferente al capitalismo. Es necesario que los estudiantes en formación entiendan la realidad social y económica de su contexto, y que los docentes y directivos diseñen programas empresariales de formación con un enfoque más estructurado de emprendimiento y nuevas alternativas rentables, tanto económicas como sociales, para que el futuro profesional sea capaz de descubrir oportunidades, apreciarlas en su justo valor, reunir los recursos necesarios y obrar para aprovecharlas.

Construir gradualmente una formación con parámetros que involucran la responsabilidad social y un conocimiento propio sobre el entorno real, contribuye a que el talento humano se constituya en eje trascendental sostenible en los retos de una economía abierta. La adecuada formación y capacitación que reciban los futuros empresarios hoy se verá reflejada en la acumulación y puesta en práctica del nuevo conocimiento. El aprendizaje fundamentado en lo social y en lo productivo trascenderá hacia nuevas alternativas empresariales, conducentes a enfrentar los efectos de una nueva etapa en el proceso de expansión internacional del país y de cada región.

El Documento del Consejo Nacional de Política Económica y Social (Conpes), en el apartado "Política Nacional de Ciencia y Tecnología" (2000-2002), menciona que la formación del capital humano constituye un elemento central para el vínculo efectivo entre ciencia y desarrollo, además, depende de la interacción educación-investigación en el proceso de generación y adaptación del conocimiento. Una formación de alto nivel y calidad, en el contexto real regional es la condición que favorecería la producción y socialización del conocimiento, de acuerdo con las necesidades económicas y sociales.

La globalización y los avances tecnológicos son la base para competir y llegar a nuevos mercados; por ello es necesario contar con un talento humano cuyas características sean flexibles, y no sólo tenga la capacidad de adaptarse, sino también la preparación necesaria para enfrentar los cambios permanentes, tanto tecnológicos como organizacionales. Es necesario que en países emergentes como Colombia se imparta una formación que apropie, no sólo conocimientos y competencias, sino también capacitación en el manejo de la complejidad del entorno y los diferentes modelos empresariales (con y sin ánimo de lucro), que sirvan para atender la nueva demanda. También es preciso hacer mayor énfasis en las formas de gestión organizacional y social, de acuerdo con un pensamiento crítico y eficaz, capaz de resolver problemas reales de su medio.

En la era actual del conocimiento, de las nuevas tecnologías y del vertiginoso proceso de globalización, 
el capital intelectual se convierte en factor clave de la empresa. Identificar este conjunto de activos intangibles de una organización puede llegar a generar un valor estratégico de competitividad sostenible, siempre y cuando sea tratado como factor de producción e innovación. Es importante fomentar la innovación y generar la interacción entre las instituciones de educación superior -generadoras de conocimiento científico, de nuevas tecnologías y productoras de la sensibilidad social en los jóvenes-, el sector productivo -demandante de la innovación, generador del desarrollo económico y social- y el Estado -partícipe de los procesos de desarrollo regional, políticas sectoriales y en las medidas de acumulación de capital.

Por tanto, analizar cómo la formación y conocimiento del talento humano se constituye en eje trascendental sostenible, mediante el desarrollo del liderazgo gerencial de las personas que se encuentran frente a las empresas, sean o no de carácter lucrativo, se hace necesario en esta aceleración de los últimos años, debido a la transformación de mercados más abiertos, especialmente para los países de América Latina. Éstos serán obligados a generar nuevas estrategias, aún más para aquellas micro, pequeñas o medianas empresas que tienen el reto de mantener el equilibrio entre la organización realizable económica y socialmente comprometida. Es así como la adecuada formación y capacitación que reciban los futuros empresarios hoy se verá reflejada mediante el proceso de acumulación de conocimiento, despertando mayor interés y generando más talento y competencia laboral para las empresas sociales.

Este aprendizaje social y productivo trascenderá, seguramente y de forma adecuada, hacia nuevas alternativas empresariales conducentes a enfrentar los efectos de una nueva etapa en el proceso de expansión internacional de un país o una región, convirtiendo a estas empresas en un medio importante de participación democrática, con una relación laboral estable y competitiva. Una nueva cultura académica, capaz de entender la necesidad local o regional, y que busca con nuevas ideas dar respuesta al sector productivo, también debe ser responsable de generar nuevos planes de negocios, promover nuevas empresas y nuevos métodos de desarrollo económico conexo con el social, en el que el estudiante o futuro profesional aprenda y participe activamente en los procesos organizacionales solidarios y tenga la opción de escoger la estructura que más le interese. De esta manera, las instituciones de educación superior amplían su misión económica y social en el entorno.

Es importante generar espacios propicios para divulgar lo que se está haciendo en materia de economía social y solidaria, y fortalecer un sector comprometido con el desarrollo del microemprendimiento, en la construcción de la cohesión social y el impulso del desarrollo humano y el crecimiento económico. Lo que conduce a que sea responsabilidad de todos virar el mundo hacia un comportamiento más equitativo y construir una economía más humana. La responsabilidad de la economía solidaria como agente de desarrollo es impulsar el espíritu empresarial comunitario desde la academia. A mayor educación, más y mejor empleo, alternativas de puestos de trabajo y menos miseria, lo que con seguridad generaría un mejor bienestar social.

\section{Referencias}

Banco Mundial. Estadísticas de inflación por país 2000-2004. Recuperado en 2006 de: http: www. worldbank.org.

Colombia. Departamento Administrativo Nacional de Estadística (DANE). Población informal ocupada. Recuperado en 2002 de: http: //www.dane.gov. $\mathrm{CO} /$.

Colombia. Departamento Administrativo Nacional de Estadística (DANE). Ingresos laborares. Recuperado en 2004 de: http: //www.dane.gov.co/.

Colombia. Departamento Nacional de Planeación (DNP). (2000). Política Nacional de Ciencia y Tecnología 2000-2002. En Documento CONPES 
(Consejo Nacional de Política Económica y Social), 3080. Bogotá: DNP.

Comisión Económica para América Latina (Cepal). Anuario estadístico 2002-2003. En Desarrollo social y bienestar. Recuperado en 2003 de: http:// www.cepal.org/publicaciones/estadísticas/.

Comisión Económica para América Latina (Cepal). Boletín demográfico. En Desarrollo social y bienestar (pp. 173-177). Recuperado en 2003 de: http:// www.cepal.org/publicaciones/Población/.

Comisión Económica para América Latina (Cepal). Una agenda para la era global. En Revista Globalización y Desarrollo (Capítulo 4. Parte I: Visión Global, pp. 113-116). Recuperado en 2002 de: http://www. cepal.org/publicaciones.

Confederación de Entidades para la Economía Social de Andalucía (CEPES). Recuperado en 2007 de: http://www.cepes.es.

Dávila Ladrón de Guevara, R. et al. (2005). Éxito e innovación en la gestión; las cooperativas como agentes del desarrollo local. San Gil, Colombia: Pontificia Universidad Javeriana, Unisangil y Unircoop.

DINI, Marco. Enfoques conceptuales para el estudio de pequeñas y medianas empresas. Mimeo, Cepal, Santiago de Chile. 1997.

El Cooperativismo, herramienta social contra el subdesarrollo (12 de mayo de 2007). El Tiempo.

Eurostat. (5 de diciembra de 2003). _The GDP in the World 2002. Economy and Finance. Statistics in Focus.

Fondo Monetario Internacional. World Economic Outlook Database Sept. 2004. The Global Demographic Transition. En World Economic and Financial Surveys. Recuperado de: http://www.imf.org/ external/pubs/ft/weo/2004/02/data/index.htm.
Fondo Monetario Internacional. World Economic Outlook Database April 2003. Inflation (Annual Percent Change). En World Economic and Financial Surveys. Recuperado de: http://www.imf.org/ external/pubs/ft/weo/2003/01/data/\#7.

Fondo Monetario Internacional. World Economic Outlook October 2001: The Information Technology Revolution (Paperback). En World Economic and Financial Surveys. Recuperado de: http://www. imf.org/external/Pubs/FT/weo/2001/02/.

Maturana, H. (1998). El árbol del conocimiento: Las bases biológicas del entendimiento humano. Editorial Lumen.

Max N., M. (2004). Conferencia: Educación y valores del espíritu y crisis del neoliberalismo. Cali, Colombia: Universidad Santiago de Cali.

Organización Internacional de Trabajo (OIT). Panorama Laboral 2005 América Latina y el Caribe. En Avance primer semestre. Recuperado en 2006: http:// www.ilo.org/public/.

Organización para la Cooperación y Desarrollo Económico (OCDE). Base de Datos de 2001.

Osorio, L. (2004). Cuadernillos universitarios. Manfred Max Neef, USC. Santiago de Cali.

Osorio, L. (2005). Estado del bienestar y economía social en América Latina. Una visión general. Tesis doctoral, Universidad de Sevilla.

Osorio, L. (2007) Las Empresas de economía social. Su papel en la redefinición de Estado del bienestar: lecciones a partir de la experiencia en el Valle del Cauca - Colombia. Tesis Doctoral, Universidad de Sevilla.

Pineda, C.J. (2000). Las empresas de la economía solidaria en Ibero América. Bogotá: Editorial Mc Graw Hill. 
Villaveces, J. (Septiembre de 2007). ¿Por qué hacer investigación en la Universidad? Revista Nota Uniandina, 22, 24-26.

Sen, A. (1999). Capacidad y bienestar (obra original publicada en 1987). Delhi: Oxford India Paperbacks.
Sen, A. (1996). Capacidad y bienestar. En M.C. Nussbaum \& A. Sen (compiladora). La calidad de vida. México: Fondo de Cultura Económica.

Senge, P. (1994). La quinta disciplina: el arte y la práctica de la organización abierta del aprendizaje. Editorial Gránica. . 